\section{Correspondence on 'Increased risk of systemic lupus erythematosus in patients with autoimmune haemolytic anaemia: a nationwide population-based cohort study'}

We read with great interest a letter by Mo et al ${ }^{1}$ pointing out that patients with autoimmune haemolytic anaemia (AIHA) had a significantly higher risk of systemic lupus erythematosus (SLE) than non-AIHA individuals. Considering that AIHA is clearly over-represented in patients with SLE, often occurring before the diagnosis of SLE, the authors nicely investigated the association between AIHA and SLE incidence in a nationwide, population-based, matched cohort study and demonstrated a high association $(\mathrm{HR}=54.7)$ between AIHA and SLE risk. ${ }^{1}$ SLE is a chronic, highly heterogeneous autoimmune disease, characterised by differences in autoantibody profile, serum cytokines and a multisystem involvement. ${ }^{2}$ AIHA is a highly heterogeneous pathological condition caused by the increased destruction of red cells in the presence of anti-red cell autoantibodies, due to immune system malfunction, thus resulting in severe tissue oxygenation disturbance. ${ }^{3}$ Of note, AIHA may present in association with a spectrum of infections (viral, bacterial and atypical) and is often associated with thrombocytopenia, lupus nephritis and central nervous system activity. ${ }^{4}$ Moreover, previous studies have suggested that both diseases may share some genetic and environmental factors, while oxidative stress has also been reported to be a risk factor for AIHA and SLE. ${ }^{5}$

Recently, we presented data suggesting that various shared genetic polymorphisms are associated with an increased susceptibility for both idiopathic thrombocytopenic purpura (ITP) and SLE. ${ }^{6}$ In the same framework, the current study by Mo et $a l^{1}$ poses the intriguing question concerning the putative role of a shared genetic background as regards the concurrence of AIHA and SLE. Although the genetics of SLE is very well investigated, the genetic factors involved in the development of AIHA and its underlying molecular mechanisms are still elusive. However, a limited number of studies have pointed to certain genes as potential risk factors for developing these diseases, thus suggesting a shared genetic predisposition in some cases. It has been reported that the human leucocyte antigen (HLA)-B8 and HLA-DQ6 regions are associated with both diseases, ${ }^{78}$ while single nucleotide polymorphisms of the CTLA- $4,{ }^{9}$ NFATC $1,{ }^{10}$ LT- $a,{ }^{11}$ FcgRIIa,${ }^{12}$ FOXP $3{ }^{13}$ and CARD $11^{14}$ genes have been also reported to be associated with the development of these diseases. With regard to AIHA, nine downregulated miRNAs have been detected so far ${ }^{15}$ and, interestingly, six of these (miR-20a, miR146b-5p, miR-223, miR-324-3p, miR-484 and miR-660) are also implicated in both diseases.

In conclusion, lessons learnt so far from the genetic studies focusing on AIHA and SLE suggest that these diseases appear a remarkable biological complexity. Various gene loci involved in both diseases have been identified thus far. The further identification of either shared or disease-specific genetic loci associated with both the development of AIHA and SLE as well as their specific clinical features may help better delineate the mechanisms for both diseases and properly disclose even subclinical associated conditions, in an attempt to choose the most appropriate therapy. ${ }^{7}$

\section{George N Goulielmos $\odot,{ }^{1}$ Maria I Zervou ${ }^{2}$}

${ }^{1}$ Laboratory of Molecular Pathology and Human Genetics, Department of Internal Medicine, School of Medicine, University of Crete, Rethimno, Crete, Greece
${ }^{2}$ Laboratory of Molecular Medicine and Human Genetics, Department of Internal Medicine, School of Medicine, University of Crete, Heraklion, Greece

Correspondence to Dr George N Goulielmos, Laboratory of Molecular Pathology and Human Genetics, Department of Internal Medicine, School of Medicine, University of Crete, Heraklion 700 13, Greece; goulielmos@med.uoc.gr

Contributors GNG wrote the paper. MIZ reviewed and edited the manuscript. Both authors read and approved its final form.

Funding The authors have not declared a specific grant for this research from any funding agency in the public, commercial or not-for-profit sectors.

Competing interests None declared.

Patient and public involvement Patients and/or the public were not involved in the design, or conduct, or reporting, or dissemination plans of this research.

Patient consent for publication Not required.

Provenance and peer review Not commissioned; internally peer reviewed.

(c) Author(s) (or their employer(s)) 2020. No commercial re-use. See rights and permissions. Published by BMJ.

\section{Check for updates}

To cite Goulielmos GN, Zervou MI. Ann Rheum Dis Epub ahead of print: [please include Day Month Year]. doi:10.1136/annrheumdis-2020-219321

Received 16 October 2020

Accepted 17 October 2020

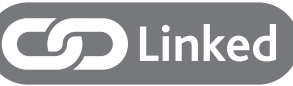

- http://dx.doi.org/10.1136/annrheumdis-2020-219328

Ann Rheum Dis 2020;0:1. doi:10.1136/annrheumdis-2020-219321

ORCID iD

George N Goulielmos http://orcid.org/0000-0002-9797-2310

\section{REFERENCES}

1 Mo H-Y, Wei JCC, Chen X-H, et al. Increased risk of systemic lupus erythematosus in patients with autoimmune haemolytic anaemia: a nationwide population-based cohort study. Ann Rheum Dis 2020:annrheumdis-2020-218886.

2 Harley JB, Kelly JA, Kaufman KM. Unraveling the genetics of systemic lupus erythematosus. Springer Semin Immunopathol 2006;28:119-30.

3 Petz LD, Garratty G. Immune hemolytic anemias. 2nd edn. Philadelphia: Churchill Livingstone, 2004.

4 Kokori SIG, loannidis JPA, Voulgarelis M, et al. Autoimmune hemolytic anemia in patients with systemic lupus erythematosus. Am J Med 2000;108:198-204.

5 Fujii J, Kurahashi T, Konno T, et al. Oxidative stress as a potential causal factor for autoimmune hemolytic anemia and systemic lupus erythematosus. World J Nephrol 2015;4:213-22.

6 Goulielmos GN, Zervou MI. Risk of systemic lupus erythematosus in patients with idiopathic thrombocytopenic purpura: population-based cohort study. Ann Rheum Dis 2020:annrheumdis-2020-218128.

7 Barcellini W, Giannotta J, Fattizzo B. Autoimmune hemolytic anemia in adults: primary risk factors and diagnostic procedures. Expert Rev Hematol 2020;13:585-97.

8 Rezaieyazdi Z, Tavakkol-Afshari J, Esmaili E, et al. Association of HLA-DQB1 allelic sequence variation with susceptibility to systemic lupus erythematosus. Iran J Allergy Asthma Immunol 2008;7:91-5

9 Pavkovic M, Georgievski B, Cevreska L, et al. Ctla-4 exon 1 polymorphism in patients with autoimmune blood disorders. Am J Hematol 2003;72:147-9.

10 Lanata CM, Nititham J, Taylor KE, et al. Genetic contributions to lupus nephritis in a multi-ethnic cohort of systemic lupus erythematous patients. PLoS One 2018;13:e0199003.

11 D'Abronzo LS, Barros MMO, Bordin JO, et al. Analysis of polymorphisms of TNF- $\alpha$, LT$\alpha$, IL-10, IL-12 and CTLA-4 in patients with warm autoimmune haemolytic anaemia. Int J Lab Hematol 2012;34:356-61.

12 Khoa PD, Sugiyama T, Yokochi T. Fc receptor II polymorphism in Vietnamese patients with systemic lupus erythematosus. Lupus 2003;12:704-6.

13 Lee HJ, Li CW, Hammerstad SS, et al. Immunogenetics of autoimmune thyroid diseases: a comprehensive review. J Autoimmun 2015;64:82-90.

14 Zheng L, Yangsheng Y Y, et al. Genetic alleles associated with SLE susceptibility and clinical manifestations in Hispanic patients from the Dominican Republic. Curr Mol Med 2019;19:164-71.

15 Ferrer G, Navarro A, Hodgson K, et al. Microrna expression in chronic lymphocytic leukemia developing autoimmune hemolytic anemia. Leuk Lymphoma 2013;54:2016-22. 